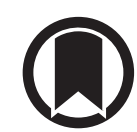

CrossMark

\section{A rational approach to e-cigarettes: challenging ERS policy on tobacco harm reduction}

\author{
To the Editor:
}

The respiratory community is united in its desire to reduce and eliminate the harm caused by tobacco smoking, which is at present on course to kill one billion people in the 21 st century. The stated policy of the European Respiratory Society is to strive "constantly to promote strong and evidence-based policies to reduce the burden of tobacco related diseases". In our view, the recent ERS Tobacco Control Committee statement on tobacco harm reduction [1], though well-intentioned, appears to be based on a number of false premises and draws its conclusions from a partial account of available data. It also presents a false dichotomy between the provision of "conventional" tobacco control and harm reduction approaches. We therefore respond, in turn, to the seven arguments presented against the adoption of harm reduction in the Committee's statement.

Argument 1: The tobacco harm reduction strategy is based on incorrect claims that smokers cannot or will not quit smoking. The strategy is in fact based on the need for additional measures to help the estimated 100 million smokers in the European Union who still have not quit. Europe has the highest smoking prevalence of all the WHO regions [2] and business as usual has, so far, failed to help these individuals. Smoking rates are significantly associated with economic disadvantage and ongoing failure to address this is a huge driver of health inequality.

Argument 2: The tobacco harm reduction strategy is based on undocumented assumptions that alternative nicotine delivery products are highly effective as a smoking cessation aid. When smokers use a nicotine replacement product to substitute for cigarettes, even in the absence of intention to quit, they are approximately twice as likely to proceed to quit smoking completely [3]. It would be astonishing if nicotine delivered via e-cigarettes was uniquely ineffective in helping people to quit smoking. In fact, in a definitive head-to-head randomised controlled clinical trial, e-cigarettes proved to be twice as effective as combination nicotine replacement therapy (NRT) when delivered as part of an evidence-based smoking cessation intervention [4], and in a recently published smaller New Zealand trial, four times more effective than nicotine patches alone [5]. Whether e-cigarettes are "highly effective" is a question of definition, but it is not an "undocumented assertion" to observe that they are certainly at least as effective as medicinal NRT $[4,5]$.

Argument 3: The tobacco harm reduction strategy is based on incorrect assumptions that smokers will replace conventional cigarettes with alternative nicotine delivery products. Harm reduction strategies do not assume that all smokers will completely switch from tobacco cigarettes to alternative products, any more than does the medicinally licensed strategy of using nicotine replacement therapy to cut down on smoking. The strategy is instead based on an initial expectation, subsequently supported by clear empirical evidence $[6,7]$, that an appreciable proportion will switch.

Argument 4: The tobacco harm reduction strategy is based on undocumented assumptions that alternative nicotine delivery products are generally harmless. No credible commentator has argued that reduced harm products are harmless. By definition, harm reduction strategies are based on reducing rather than eliminating harm and the likelihood that there is some risk from their long-term use is explicitly acknowledged in statements on the subject [8-11]. However, the fact that many of the elements found in

@ERSpublications

The current ERS Tobacco Control Committee statement rejecting harm reduction does not reflect the state of evidence around the effectiveness and safety of e-cigarettes and may be harmful if implemented http://bit.ly/39ix $5 \mathrm{iO}$

Cite this article as: Britton J, George J, Bauld L, et al. A rational approach to e-cigarettes: challenging ERS policy on tobacco harm reduction. Eur Respir J 2020; 55: 2000166 [https://doi.org/10.1183/ 13993003.00166-2020]. 
tobacco smoke that are known to cause toxicity are either absent from e-cigarette vapour or present at much lower levels [12] does support a substantial reduction in this risk. Supportive clinical data in smokers who switch to vaping include rapid improvement in vascular endothelial function [13], profound falls in systemic carcinogen levels to ones equivalent to ex-smokers using NRT [14], and improvement in respiratory symptoms [4]. Understandable concerns over safety arising from the 2019 outbreak of vaping-related lung injury in the USA have been alleviated by evidence it was caused by vaping illicit products, in particular tetrahydrocannabinol (THC) cut with vitamin E acetate [15].

Argument 5: Alternative nicotine delivery products can have a negative impact on public health even if "stick-by-stick" they turn out to be less harmful than conventional cigarettes. The argument this statement introduces is that e-cigarettes are driving increasing numbers of young people to become nicotine addicted and to go on to become smokers. In fact, experimentation with e-cigarettes occurs predominantly among young people who have already started smoking or are at increased risk of smoking [16, 17], thus representing a rational choice over the far more hazardous tobacco product. Most importantly, smoking rates among teenagers in the USA and UK are falling [18-22]. The same is true of adult smoking, which is falling in both countries [23, 24], and particularly rapidly in the UK as increasing numbers of adult smokers switch to e-cigarettes [24]. Moreover, parental smoking is one of the main drivers of child smoking uptake [22], so as e-cigarette use enables more adults to quit so fewer children will have smoking parents as role models and more children will be protected from in utero and passive smoke exposure.

Argument 6: Smokers see alternative nicotine delivery products as a viable alternative to the use of evidence-based smoking cessation services and smoking cessation pharmacotherapy. Smokers are correct to view e-cigarettes as a viable, evidence-based and proven option to aid smoking cessation $[4,5]$, and the development of novel approaches for people who have tried conventional pharmacotherapy unsuccessfully should be welcomed. It is also incorrect to regard e-cigarettes as an alternative to engaging with smoking cessation services, given the compelling evidence that combining psychological support with nicotine replacement increases quit rates. It is precisely the exclusion of people who are choosing to try to quit smoking using e-cigarettes that is likely to reduce these individuals' chances of success. Most importantly, although the statement argues that smoking cessation services "exist", in practice provision of smoking cessation services is limited $[25,26]$, more so given political choices to pursue austerity policies which reduce public health funding. Access to such services may therefore be difficult, especially for the most disadvantaged people and those with disorganised lives. Rejection of harm reduction strategies is thus likely to worsen health inequalities.

Argument 7: The tobacco harm reduction strategy is based on incorrect claims that we cannot curb the tobacco epidemic. Harm reduction complements conventional tobacco control strategies, it does not replace them. The UK leads Europe in implementing tobacco control policies, including the exclusion of the tobacco industry from influence on policy making [27] and smoking rates there have declined faster than the rest of Europe as a result [28]. Combined with a rational and regulated approach to e-cigarettes (table 1) the UK is

TABLE 1 Key messages for a rational approach to vaping and e-cigarettes

1 People smoke tobacco because of nicotine addiction, but the major harms come not from the nicotine but from toxic substances in the smoke

2 Pharmacotherapy (e.g. dual nicotine replacement therapy or varenicline) combined with psychological support should be made available to all smokers to help them to quit and should be considered as the first line approach

3 E-cigarettes are an effective means to deliver nicotine, with a much lower risk of harm than continuing to smoke

4 People who choose to use e-cigarettes to cut down or quit smoking should be offered psychological support and access to smoking cessation services

5 People who choose to use e-cigarettes should be advised that they need to switch completely in order to derive substantial health benefits

6 People using e-cigarettes should be advised to try to quit them in the long term, but not at the risk of relapsing to smoking

7 Never-smokers should avoid e-cigarettes

8 E-cigarettes should continue to be subject to restrictions on age of sale, on advertising and on the strength of e-liquids, as set out in the EU Tobacco Products Directive

9 Respiratory clinicians must continue to campaign for the full implementation of the WHO MPOWER strategy [30] designed to assist implementation of the Framework Convention on Tobacco Control, as this is the most powerful tool to deliver a smokefree generation

- Monitor tobacco use and prevention policies

- Protect people from tobacco smoke

- Offer help to quit tobacco use

- Warn about the dangers of tobacco use

- Enforce bans on tobacco advertising, promotion and sponsorship

- Raise taxes on tobacco 
now experiencing rates of decline in smoking prevalence, from $20.2 \%$ in 2011 to $14.7 \%$ in 2018 ; this decline is faster than it has been for decades [24], and in England the ambition is to reduce smoking prevalence to below 5\% across all groups by 2030. European countries in general, and the ERS in particular, should take heed of this evidence, rather than ignore it.

We believe that blanket opposition to e-cigarettes is misguided and will lead to a number of important consequences that are adverse to health. First, smokers who would otherwise have quit smoking by switching to a lower risk product will continue to smoke, and die prematurely from cancer, cardiovascular and respiratory disease. Second, people who have successfully switched to vaping may relapse to smoking if they come to believe that there is no health benefit from vaping, and thus increase their risk of avoidable morbidity and premature death. Third, the pursuit of arguments that vaping cannot help people to quit smoking, in the face of clear evidence that it does, risks undermining public trust in science.

We wholeheartedly support the call for increased efforts to deliver "what we know works". Electronic cigarette use is an epiphenomenon of smoking and current smoking levels are a consequence of past failures and delays in the implementation of tobacco control measures, including effective and accessible treatment, tax increases, smokefree legislation, advertising bans and public health campaigns [29]. We respectfully suggest that the Society reconsiders its position, so that we can focus on our shared goal to make smoking history.

John Britton ${ }^{1}$, Jacob George ${ }^{2}$, Linda Bauld ${ }^{3}$, Sanjay Agrawal ${ }^{4}$, John Moxham ${ }^{5}$, Deborah Arnott $^{6}$, Ann McNeill ${ }^{7}$ and Nicholas S. Hopkinson $\oplus^{8}$

${ }^{1}$ UK Centre for Tobacco and Alcohol Studies, University of Nottingham, London, UK. ${ }^{2}$ Molecular and Cellular Medicine, Dundee University, Dundee, UK. ${ }^{3}$ Usher Institute, College of Medicine and Veterinary Medicine, University of Edinburgh, Edinburgh, UK. ${ }^{4}$ Institute for Lung Health, University of Leicester, Leicester, UK. ${ }^{5}$ Faculty of Life Sciences and Medicine, King's College London, London, UK. ${ }^{6}$ Action on Smoking and Health (ASH UK), London, UK. ${ }^{7}$ Institute of Psychiatry, Psychology and Neuroscience, King's College London, London, UK. ${ }^{8}$ National Heart and Lung Institute, Imperial College, London, UK.

Correspondence: Nicholas Hopkinson, National Heart and Lung Institute, Imperial College, London, Royal Brompton Hospital Campus, London SW3 6NP, UK. E-mail: n.hopkinson@ic.ac.uk

Received: 16 Jan 2020 | Accepted after revision: 5 Feb 2020

Conflict of interest: J. Britton has nothing to disclose. J. George has nothing to disclose. L. Bauld has nothing to disclose. S. Agrawal chairs the Royal College of Physicians Tobacco Advisory Committee. J. Moxham has nothing to disclose. D. Arnott has nothing to disclose. A. McNeill has nothing to disclose. N.S. Hopkinson is Chair of Action on Smoking and Health (ASH UK).

\section{References}

1 Pisinger C, Dagli E, Filippidis FT, et al. ERS and tobacco harm reduction. Eur Respir J 2019; 54: 1902009.

2 World Health Organization Regional Office for Europe. Data and Statistics: Current Tobacco Smoking in Europe. World Health Organization, 2019.

3 National Institute for Health and Care Excellence. Tobacco: Harm-reduction Approaches to Smoking (PH45). NICE, 2013.

4 Hajek P, Phillips-Waller A, Przulj D, et al. A randomized trial of e-cigarettes versus nicotine-replacement therapy. N Engl J Med 2019; 380: 629-637.

5 Walker N, Parag V, Verbiest M, et al. Nicotine patches used in combination with e-cigarettes (with and without nicotine) for smoking cessation: a pragmatic, randomised trial. Lancet Respir Med 2020; 8: 54-64.

6 Action on Smoking and Health. Use of E-cigarettes Among Adults in Great Britain, 2019. https://ash.org.uk/ information-and-resources/fact-sheets/statistical/use-of-e-cigarettes-among-adults-in-great-britain-2019/ Date last updated: 2 September, 2019.

7 Beard E, West R, Michie S, et al. Association of prevalence of electronic cigarette use with smoking cessation and cigarette consumption in England: a time-series analysis between 2007 and 2017. Addiction 2019; in press [https:// doi.org/10.1111/add.14851].

8 Britton J, Bogdanovica I. Electronic Cigarettes. A Report Commissioned by Public Health England. London, Public Health England, 2014.

9 Public Health England. E-cigarettes: a Developing Public Health Consensus. London, Public Health England, 2016.

10 National Academies of Sciences Engineering and Medicine. Public Health Consequences of E-cigarettes. Washington, National Academies Press, 2018.

11 Tobacco Advisory Group of the Royal College of Physicians. Nicotine Without Smoke-Tobacco Harm Reduction. www.rcplondon.ac.uk/projects/outputs/nicotine-without-smoke-tobacco-harm-reduction Date last accessed: January 10, 2020.

12 Goniewicz ML, Knysak J, Gawron M, et al. Levels of selected carcinogens and toxicants in vapour from electronic cigarettes. Tob Control 2014; 23: 133-139.

13 George J, Hussain M, Vadiveloo T, et al. Cardiovascular effects of switching from tobacco cigarettes to electronic cigarettes. J Am Coll Cardiol 2019; 74: 3112-3120.

14 Shahab L, Goniewicz ML, Blount BC, et al. Nicotine, carcinogen, and toxin exposure in long-term e-cigarette and nicotine replacement therapy users: a cross-sectional study. Ann Intern Med 2017; 166: 390-400.

15 Centers for Disease Control and Prevention. Outbreak of Lung Injury Associated with the Use of E-Cigarette, or Vaping, Products. www.cdc.gov/tobacco/basic_information/e-cigarettes/severe-lung-disease.html Date last accessed: January 10, 2020. 
16 Action on Smoking and Health. Use of Electronic Cigarettes Among Young People in Great Britain, 2019. https:// ash.org.uk/wp-content/uploads/2019/06/ASH-Factsheet-Youth-E-cigarette-Use-2019.pdf Last updated June 2019.

17 West R, Brown J, Jarvis M. Epidemic of youth nicotine addiction? What does the National Youth Tobacco Survey reveal about high school e-cigarette use in the USA? Qeios 2019; preprint [https://doi.org/10.32388/745076.2].

18 NHS Digital. Smoking drinking and drug use among young people in England in 2018. London, NHS Digital, 2019.

19 Gentzke AS, Creamer M, Cullen KA, et al. Vital signs: tobacco product use among middle and high school students-United States, 2011-2018. MMWR Morb Mortal Wkly Rep 2019; 68: 157-164.

20 Wang TW, Gentzke AS, Creamer MR, et al. Tobacco product use and associated factors among middle and high school students-United States, 2019. MMWR Surveillance Summaries 2019; 68: 1.

21 Hopkinson NS, Lester-George A, Ormiston-Smith N, et al. Child uptake of smoking by area across the UK. Thorax 2014; 69: 873-875.

22 Laverty AA, Filippidis FT, Taylor-Robinson D, et al. Smoking uptake in UK children: analysis of the UK Millennium Cohort Study. Thorax 2019; 74: 607-610.

23 Centers for Disease Control and Prevention. Current Cigarette Smoking Among Adults in the United States. Centers for Disease Control and Prevention, 2019.

24 Office for National Statistics. Adult Smoking Habits in Great Britain 2018. Office for National Statistics, 2019.

25 Royal College of Physicians. Hiding in Plain Sight: Treating Tobacco Dependency in the NHS. London, Royal College of Physicians, 2018. Available from: www.rcplondon.ac.uk/projects/outputs/hiding-plain-sight-treatingtobacco-dependency-nhs

26 Filippidis FT, Laverty AA, Mons U, et al. Changes in smoking cessation assistance in the European Union between 2012 and 2017: pharmacotherapy versus counselling versus e-cigarettes. Tob Control 2019; 28: 95-100.

27 Joossens L, Raw M. The Tobacco Control Scale 2016 in Europe. Brussels, Association of European Cancer Leagues, 2017.

28 Feliu A, Filippidis FT, Joossens L, et al. Impact of tobacco control policies on smoking prevalence and quit ratios in 27 European Union countries from 2006 to 2014. Tob Control 2019; 28: 101-109.

29 Hopkinson NS. The prominence of e-cigarettes is a symptom of decades of failure to tackle smoking properly. BMJ 2019; 364: 1647.

30 Dubray J, Schwartz R, Chaiton M, et al. The effect of MPOWER on smoking prevalence. Tob Control 2015; 24: $540-542$

From the authors:

We wish to thank J. Britton and co-workers for responding to our editorial and giving us an opportunity to clarify our position as well as correct a few misunderstandings. We definitely share the same goal, which is to relieve Europe and the rest of the world from the terrible results of the tobacco epidemic. We also do not "blankly oppose e-cigarettes"; however, we strongly advocate against a harm reduction strategy including e-cigarettes as well as heated tobacco products [1]. As clinicians we all see reluctant smokers where e-cigarettes can be tried as a last resort for getting off cigarette smoking, but that is of little relevance for a general harm reduction strategy. We also agree that the UK has achieved a lot in the area of smoking cessation but would argue that this has been achieved by impressive tobacco control, not by the use of e-cigarettes, and that a country such as Australia, which has banned nicotine-containing e-cigarettes, has achieved similar results.

J. Britton and co-workers commented on our seven responses to what we consider flawed arguments for e-cigarettes as part of harm reduction in public health. Below is our rebuttal.

Argument 1: The tobacco harm reduction strategy is based on incorrect claims that smokers cannot or will not quit smoking. We entirely agree that more efforts are needed in tobacco control; however, smoking prevalence has been declining for decades in most European countries. Proper access to smoking cessation advice, approved free cessation drugs and nicotine replacement therapy (NRT) should be made available to the majority of smokers who want to quit their nicotine addiction, which will have a major impact on the prevalence of smoking. We may as a community have failed in pointing this out to politicians as investment in tobacco control seems to be fading [2]. Excellence in this area could easily be achieved for a fraction of what is currently being spent on marketing and advertising for e-cigarettes and other

@ERSpublications

Regarding the use of alternative nicotine delivery systems, ERS argues that including e-cigarettes in a harm reduction strategy is not evidence-based and may result in harm. Instead, we should support access to evidence-based smoking cessation methods. http://bit.ly/2TpUCYG

Cite this article as: Pisinger C, Vestbo J. A rational approach to e-cigarettes: challenging ERS policy on tobacco harm reduction. Eur Respir J 2020; 55: 2000355 [https://doi.org/10.1183/13993003.00355-2020]. 
alternative nicotine delivery systems. We too find, that it is a great public challenge that the burden of smoking-related disease is higher among disadvantaged groups. However, evidence of the effect of e-cigarette use to reduce health inequalities is lacking; recent studies show the opposite effect [3].

Argument 2: The tobacco harm reduction strategy is based on undocumented assumptions that alternative nicotine delivery products are highly effective as a smoking cessation aid. None of the alternative nicotine delivery products have been approved as tools for smoking cessation. In the trial mentioned [4] it is correct that quit rates were twice as high in the e-cigarette group than in the standard NRT group. However, most participants in the e-cigarette group continued to use e-cigarettes, thereby exposing their lungs to harmful substances, and many ended up with dual use (using both cigarettes and e-cigarettes). Furthermore, large real-world studies strongly indicate that use of e-cigarettes undermines, not promotes, abstinence from smoking $[5,6]$.

Argument 3: The tobacco harm reduction strategy is based on incorrect assumptions that smokers will replace conventional cigarettes with alternative nicotine delivery products. We agree with J. Britton and co-workers that harm reduction strategies do not assume that all smokers will completely switch from tobacco cigarettes to alternative products and we have not claimed that. We cannot, however, ignore the fact that most individuals use alternative nicotine delivery products as a supplement to conventional cigarettes (without reducing number of cigarettes substantially), not as an alternative to smoking [7]. Therefore, there will be no health benefit for most smokers.

Argument 4: The tobacco harm reduction strategy is based on undocumented assumptions that alternative nicotine delivery products are generally harmless. In the UK, the National Health Service website on smoking cessation states that e-cigarettes are at least 95\% less harmful than cigarettes [8]; this is in our perception in concordance with "generally harmless", as we wrote. Vaping introduces inhalation of compounds that have not been properly tested and risk therefore not assessed. Many studies have shown that the respiratory response to vaping is far more pronounced than " $5 \%$ of that of cigarettes", in some cases fairly similar [9-11]. Thus, the whole basis for this commonly cited statistic is dubious [12]. We admit that the long-term clinical consequences are unclear, and the uncertainty itself makes these products unsuitable for widespread use.

Regarding the US outbreak of e-cigarette, or vaping, product use-associated lung injury (EVALI), the Center for Disease Control states that "However, evidence is not sufficient to rule out the contribution of other chemicals of concern, including chemicals in either THC or non-THC products, in some of the reported EVALI cases" [13]. In European cases reported, neither tetrahydrocannabinol (THC) nor vitamin E seems to have played a major role.

Argument 5: Alternative nicotine delivery products can have a negative impact on public health even if "stick-by-stick" they turn out to be less harmful than conventional cigarettes. We are of course happy if e-cigarette use in teenagers in the UK predominantly occurs in those who already smoke although we note that the number of vaping teenagers has tripled in the past 5 years [14] and that a school-based study from UK found that more than half of e-cigarette users had never used tobacco [15]. Among US e-cigarette users aged 18-24 years in 2015, 40.0\% had never been regular cigarette smokers [14]. Use of conventional cigarettes has decreased from $9 \%$ in 2014 to $6 \%$ in 2019 in US high school students, while use of e-cigarettes has risen from $13 \%$ to $27.5 \%$ in the same period [16]. It is therefore difficult to follow the argument that e-cigarettes divert youth from cigarettes.

Widespread use of vaping in the public space may also "normalise" inhaling of a nicotine product, a sight that was getting increasingly rare in the UK and elsewhere. We can only guess what that means for future health behaviour but we already know that young adult smokers get the same urge to smoke when they see someone vape as when they see someone smoke and this could therefore have a negative impact on smoking cessation rates [17].

Argument 6: Smokers see alternative nicotine delivery products as a viable alternative to the use of evidence-based smoking cessation services and smoking cessation pharmacotherapy. We mislead smokers if we pretend that the evidence base and safety of e-cigarettes is comparable to that of approved tools such as NRT and varenicline. We agree with J. Britton and co-workers that access to combined NRT/varenicline and psychosocial support is insufficient. Where we disagree is that we find it irresponsible to offer e-cigarettes as a tool, as this will only reinforce the perception that the more costly, but highly efficient, cessation methods are unobtainable. Maintaining nicotine addiction through the use of e-cigarettes will likely not reduce social health inequality.

Argument 7: The tobacco harm reduction strategy is based on incorrect claims that we cannot curb the tobacco epidemic. J. Britton and co-workers state that the UK leads Europe in implementing tobacco control policies. We agree and would hope that many European countries will follow many of the 
elements of the UK success. These include the exclusion of the tobacco industry from influence on policy making, tobacco display bans, large graphic health warnings on packs, plain packaging, increased tobacco taxes and minimum pack sizes. We would argue that if all the above evidence-based interventions, known to be free of harm and implemented, were implemented across the EU as they have been in the UK, we would be doing the 100 million smokers in the EU a huge favour. Some of us already use the UK as a shining example [18]. However, all these factors likely play a determining role in the decrement in smoking that so many e-cigarette advocates now ascribe to the sensible British use of e-cigarettes. Also, countries like the USA and Australia, with respectively $2.4 \%$ and $0.8 \%$ vapers, have experienced similar decline in smoking rates as the UK where $6.2 \%$ of the population is vaping.

We still agree with J. Britton and co-workers that more is needed to relieve the population in Europe and elsewhere from the perils of cigarette smoking. If e-cigarettes had been tested in randomised controlled trials similar to those required for smoking cessation drugs and were found to be as efficacious, if they were on prescription, and if they came in neutral packages and without all the artificial flavours, we would actually welcome them as an additional smoking cessation tool to the few reluctant smokers. This would be in consistence with the original harm reduction strategy (for e.g. drug addicts), aimed at those few we otherwise would give up upon. However, we will maintain that a harm reduction strategy in tobacco control is inappropriate at population level and that the inadequately regulated market for e-cigarettes and other alternative nicotine delivery products pose harm to non-smokers, in particular children and adolescents.

We also maintain that quitting smoking and quitting nicotine should go hand in hand. In the UK, half of vapers are smoking on a daily basis [12]. E-cigarettes will therefore not reduce the craving for nicotine in smokers and may actually stimulate new addiction in those who have never smoked. To us, this seems like an ideal scenario for any tobacco company and likely explains their huge investments in alternative nicotine delivery systems.

Charlotta Pisinger ${ }^{1}$ and Jørgen Vestbo $\odot^{2,3}$, on behalf of the ERS Tobacco Control Committee and ERS Senior Leadership

${ }^{1}$ Center for Clinical Research and Disease Prevention, Frederiksberg-Bispebjerg University Hospital, Copenhagen, Denmark. ${ }^{2}$ Division of Infection, Immunity and Respiratory Medicine, University of Manchester, Manchester, UK. ${ }^{3}$ North West Lung Centre, Manchester University NHS, Foundation Trust, Manchester, UK.

Correspondence: Jørgen Vestbo, 2nd Floor, ERC Building, Wythenshawe Hospital, Southmoor Road, Manchester, M23 9LT, UK. E-mail: jorgen.vestbo@manchester.ac.uk

Received: 18 Feb 2020 | Accepted after revision: 18 Feb 2020

Conflict of interest: C. Pisinger has nothing to disclose. J. Vestbo reports personal fees for consultancy from AstraZeneca, grants and personal fees for consultancy and lectures from Boehringer Ingelheim, personal fees for consultancy and lectures from Chiesi, GSK and Novartis, outside the submitted work; and has a family member who is an employee of Chiesi.

\section{References}

Pisinger C, Dagli E, Filippidis FT, et al. ERS and tobacco harm reduction. Eur Respir J 2019; 54: 1902009.

Iacobucci G. Stop smoking services: BMJ analysis shows how councils are stubbing them out. BMJ 2018; 362: k3649.

3 Harlow AF, Stokes A, Brooks DR. Socioeconomic and racial/ethnic differences in e-cigarette uptake among cigarette smokers: longitudinal analysis of the Population Assessment of Tobacco and Health (PATH) study. Nicotine Tob Res 2019; 21: 1385-1393.

4 Hajek P, Phillips-Waller A, Przulj D, et al. A randomized trial of e-cigarettes versus nicotine-replacement therapy. N Engl J Med 2019; 380: 629-637.

5 Kalkhoran S, Glantz SA. E-cigarettes and smoking cessation in real-world and clinical settings: a systematic review and meta-analysis. Lancet Respir Med 2016; 4: 116-128.

6 Gorini G, Ferrante G, Quarchioni E, et al. Electronic cigarette use as an aid to quit smoking in the representative Italian population PASSI survey. Prev Med 2017; 102: 1-5.

7 Beard E, Brown J, Michie S, et al. Is prevalence of e-cigarette and nicotine replacement therapy use among smokers associated with average cigarette consumption in England? A time-series analysis. BMJ open 2018; 8: e016046.

8 National Health Service. E-cigarettes/vapes. www.nhs.uk/smokefree/help-and-advice/e-cigarettes. Date last accessed: 7 February 2020.

9 Scott A, Lugg ST, Aldridge K, et al. Pro-inflammatory effects of e-cigarette vapour condensate on human alveolar macrophages. Thorax 2018; 73: 1161-1169.

10 Chung S, Baumlin N, Dennis JS, et al. Electronic cigarette vapor with nicotine causes airway mucociliary dysfunction preferentially via TRPA1 receptors. Am J Respir Crit Care Med 2019; 200: 1134-1145.

11 Ghosh A, Coakley RD, Ghio AJ, et al. Chronic e-cigarette use increases neutrophil elastase and matrix metalloprotease levels in the lung. Am J Respir Crit Care Med 2019; 200: 1392-1401.

12 Gornall J. Public Health England's troubled trail. BMJ 2015; 351: h5826. 
13 Centers for Disease Control and Prevention. Outbreak of Lung Injury Associated with the Use of E-Cigarette, or Vaping, Products. www.cdc.gov/tobacco/basic_information/e-cigarettes/severe-lung-disease.html. Date last accessed: 7 February 2020. Date last updated: 25 February 2020.

14 Action on Smoking and Health. Use of E-cigarettes Among Adults in Great Britain, 2019. https://ash.org.uk/ information-and-resources/fact-sheets/statistical/use-of-e-cigarettes-among-adults-in-great-britain-2019/ Date last accessed: 7 February 2020. Date last updated: 2 September, 2019.

15 Fulton E, Gokal K, Griffiths S, et al. More than half of adolescent E-cigarette users had never smoked a cigarette: findings from a study of school children in the UK. Public Health 2018; 161: 33-35.

16 Cullen KA, Gentzke AS, Sawdey MD, et al. e-Cigarette use among youth in the United States, 2019. JAMA 2019; 322: 2095-2103.

17 King AC, Smith LJ, McNamara PJ, et al. Second generation electronic nicotine delivery system vape pen exposure generalizes as a smoking cue. Nicotine Tob Res 2018; 20: 246-252.

18 Vestbo J, Pisinger C, Bast L, et al. Forebyggelse af rygning blandt børn og unge. Hvad virker? [Prevention of smoking among children and adolescents. What works?]. Copenhagen, Vidensråd for Forebyggelse, 2018; pp. 1-124.

\title{
The ERS approach to e-cigarettes is entirely rational
}

\author{
To the Editors:
}

The call for the European Respiratory Society (ERS) to change their e-cigarette and vaping policy, from honourable people with decades of experience fighting the evils of tobacco, is unfortunately misconceived. The three issues of greatest concern are acute toxicity, chronic toxicity and, most importantly, the effects on children and young people. The efficacy of e-cigarettes as an adjunct to smoking cessation are outwith the expertise of paediatric specialists, but we would ask for assurances that any benefits really do outweigh the risks to children and young people (below). Our comments on these key issues are as follows:

1) Acute toxicity: e-cigarette or vaping induced acute lung injury (EVALI) is an increasingly common entity [1] with near- or actual fatalities reported [1,2]. The mechanism is unclear. Many but not all reported EVALI cases are related to the addition of cannabinoids. The abuse by children and young people of the hardware used for vaping, of itself, also gives rise to important safety concerns. It is wrong to assert that the acute toxicity of e-cigarettes per se is less than that of tobacco.

2) Chronic toxicity: the absence of tar and carbon monoxide from e-cigarettes is unequivocally to be welcomed [3]. However, in vitro data demonstrate that vaping liquids have their own unique toxicities in addition to those that overlap with tobacco [4]. There are now tens of thousands of "legal" fluids on the market containing a myriad of ingredients and the numbers are growing rapidly; for example, 7764 flavour labels were available on websites in 2013-2014; in 2016-2017 it was more than double, at 15586 [5]. Some products are known to contain substances that are toxic to the respiratory tract and are in breach of European tobacco legislation [6]. Indeed, medium-term toxicities of e-cigarettes are already emerging [7]. It took decades for many of the harmful effects of conventional cigarettes to be elucidated and new concerns continue to arise. The important lesson from cigarette smoking is that it is impossible to make a rational assessment about the long-term risks of e-cigarettes.

3) The effects on children and young people: Our biggest concern is the public health emergency of e-cigarette uptake by children and young people. This is a child protection issue that the UK is failing to confront. As argued elsewhere [3], whether e-cigarettes are a gateway to smoking is irrelevant; they are a journey's end for nicotine addiction, with all the adverse effects of that chemical. E-cigarette uptake by children and young people has grown exponentially in the USA [8]. Their highly positive social media profile outstrips warnings against their use [9-11]. E-cigarette manufacturers have been found guilty of deliberately targeting young people by the US Food and Drug Administration [12]. The UK is not the USA, but it would be foolish to ignore what is 
happening there. We welcome the focus of the next World Tobacco Day on preventing children being exposed to all forms of nicotine. If adult physicians continue to advocate for vaping as a means of harm reduction in adults, there must also be a coherent policy in place for protecting children.

The ERS policy aligns with those of the Federation of International Respiratory Societies [13], the American Academy of Paediatrics [14] and many other bodies. We believe its current statements are absolutely correct and should not be changed.

Andrew Bush ${ }^{1}$, Jayesh Mahendra Bhatt $\odot^{2}$, Will Carroll ${ }^{3}$, Frances Child ${ }^{4}$, Gary Connett ${ }^{5}$, Iolo Doull ${ }^{6}$, Francis Gilchrist $\oplus^{7,8}$, Jonathan Grigg ${ }^{9}$, Simon Langton-Hewer ${ }^{10}$, Julian Legg ${ }^{11}$, Warren Lenney ${ }^{12}$, James Paton ${ }^{13}$, Michael Shields ${ }^{14}$ and Ian Sinha ${ }^{15}$

${ }^{1}$ Imperial College, National Heart and Lung Institute, Royal Brompton and Harefield NHS Foundation Trust, London, UK. ${ }^{2}$ Paediatric Respiratory Medicine, Nottingham Children's Hospital, Nottingham University Hospitals NHS Trust, Nottingham Children's Hospital, Nottingham, UK. ${ }^{3}$ Paediatrics, Derby Hospitals NHS Trust, University Hospitals of North Midlands NHS Trust, Stoke-on-Trent, UK. ${ }^{4}$ Dept of Respiratory Paediatrics, Central Manchester and Manchester Children, Manchester, UK. ${ }^{5}$ University Hospital Southampton NHS Foundation Trust, University Hospital Southampton, Southampton, UK. ${ }^{6}$ Children's Hospital for Wales, Cardiff, UK. ${ }^{7}$ Paediatric Respiratory Services, University Hospitals of North Midlands NHS Trust, Royal Stoke University Hospital, Stoke-on-Trent, UK. ${ }^{8}$ Institute of Applied Clinical Science, Keele University, Keele, UK. ${ }^{9}$ Centre for Paediatrics, Queen Mary University London, London, UK. ${ }^{10}$ Respiratory Medicine, Bristol Royal Hospital for Children, Bristol, UK. ${ }^{11}$ Southampton University Hospitals NHS Trust, Southampton, UK. ${ }^{12}$ Academic Department of Child Health, University Hospital of North Staffordshire and Keele University, Stoke-on-Trent, UK. ${ }^{13}$ Royal Hospital for Sick Children, Glasgow, UK. ${ }^{14}$ Centre for Experimental Medicine, Queen's University Belfast, Belfast, UK. ${ }^{15}$ Alder Hey Children's NHS Foundation Trust, Liverpool, UK.

Correspondence: Andrew Bush, National Heart and Lung Institute, Royal Brompton and Harefield NHS Foundation Trust, Sydney Street, London NW103BJ, UK. E-mail: a.bush@rbht.nhs.u

Received: 24 Feb 2020 | Accepted after revision: 25 Feb 2020

Conflict of interest: A. Bush has nothing to disclose. J.M. Bhatt has nothing to disclose. W. Carroll has nothing to disclose. F. Child has nothing to disclose. G. Connett has nothing to disclose. I. Doull has nothing to disclose. F. Gilchrist has nothing to disclose. J. Grigg reports personal fees for consultancy from BV Pharma, GSK, AstraZeneca and Novartis, outside the submitted work. S. Langton-Hewer has nothing to disclose. J. Legg has nothing to disclose. W. Lenney has nothing to disclose. J. Paton has nothing to disclose. M. Shields has nothing to disclose. I. Sinha has nothing to disclose.

\section{References}

1 Hsewn Y, Brownstein JS. Real-time digital surveillance of vaping-induced pulmonary disease. N Engl J Med 2019; 381: $1778-1780$.

2 Nair N, Hurley M, Gates S, et al. Life-threatening hypersensitivity pneumonitis secondary to e-cigarettes. Arch Dis Child 2019; in press [https://doi.org/10.1136/archdischild-2019-317889].

3 Bush A, Bhatt J, Grigg J. E cigarettes: Tar Wars: The (Tobacco) Empire Strikes Back. Arch Dis Child 2019; 104: 1027-1039.

4 Ghosh A, Coakley RC, Mascenik T, et al. Chronic e-cigarette exposure alters the human bronchial epithelial proteome. Am J Respir Crit Care Med 2018; 198: 67-76.

5 Hsu G, Sun JY, Zhu S-H. Evolution of electronic cigarette brands from 2013-2014 to 2016-2017: analysis of brand websites. J Med Internet Res 2018; 20: e89.

6 Vardavas C, Girvalaki C, Vardavas A, et al. Respiratory irritants in e-cigarette refill liquids across nine European countries: a threat to respiratory health? Eur Respir J 2017; 50: 1701698.

7 Bhatta DN, Glantz SA. Association of e-cigarette use with respiratory disease among adults: a longitudinal analysis. Am J Prevent Med 2020; 58: 182-190.

8 King BA, Jones CM, Baldwin GT, et al. The EVALI and youth vaping epidemics-implications for public health. N Engl J Med 2020; 382: 689-691.

9 Allem JP, Majmundar A, Dharmapuri L, et al. E-liquid-related posts to Twitter in 2018: thematic analysis. Addict Behav Rep 2019; 10: 100196

10 Laestadius LI, Penndorf KE, Seidl M, et al. Assessing the appeal of Instagram electronic cigarette refill liquid promotions and warnings among young adults: Mixed Methods Focus Group Study. J Med Internet Res 2019; 21: e15441.

11 Vassey J, Metayer C, Kennedy CJ, et al. \#Vape: measuring e-cigarette influence on Instagram with deep learning and text analysis. Front Communn 2020; 4: 75.

12 US Food and Drug Administration. Statement from FDA Commissioner Scott Gottlieb, M.D., on New Enforcement Actions and a Youth Tobacco Prevention Plan to Stop Youth Use of, and Access to, JUUL and Other E-Cigarettes. www.fda.gov/newsevents/newsroom/pressannouncements/ucm605432.htm Date last updated: 23 April 2018.

13 Ferkol TW, Farber HJ, La Grutta S, et al. Electronic cigarette use in youths: a position statement of the Forum of International Respiratory Societies. Eur Respir J 2018; 51: 1800278.

14 American Academy of Pediatrics. AAP Policy Statement: E-Cigarettes Need Stronger Regulations to Prevent Youth Access and Use. www.aap.org/en-us/about-the-aap/aap-press-room/Pages/AAP-Policy-Statement-E-CigarettesNeed-Stronger-Regulations-to-Prevent-Youth-Access-and-Use.aspx Date last updated: 28 January 2019. 